\title{
Test-retest reliability of the Health Literacy Questionnaire (HLQ-Br) in Brazilian carers of older people
}

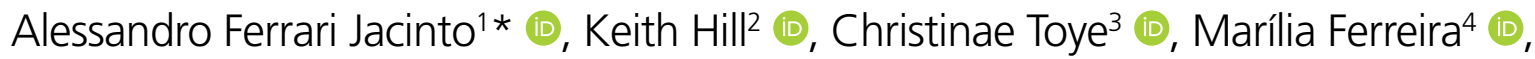 \\ Aline Bertoni ${ }^{4}\left(\mathbb{D}\right.$, Susan Slatyer ${ }^{5}$ (1), Elissa Burton ${ }^{3}$
}

\section{INTRODUCTION}

The rapid aging of the Brazilian population is seeing people living longer but with comorbidities more common in older people and higher dependence in activities of daily living. Due to these factors, support from formal and informal carers is needed more frequently. Many informal carers are family members who manage the health of the older person they are caring for, including accompanying them to medical appointments and advocating for them when they are hospitalized ${ }^{1,2}$. As such, carers of older people often have a key role in accessing, understanding and supporting the implementation of health-related recommendations for the older person they provide care for.

According to the U.S. Department of Health and Human Services, health literacy is defined as "the degree to which individuals can obtain, process, and understand basic health information needed to make appropriate health decisions" ${ }^{3}$. Carers with low levels of health literacy may fail to implement the recommendations of health professionals, thus compromising care ${ }^{4}$. Data on health literacy in Brazilian carers of older people is scarce. In a previous study on health literacy in carers of older people in Brazil, one-third of the carers of older patients assessed in an outpatient clinic had low health literacy ${ }^{5}$.

The Health Literacy Questionnaire (HLQ) is an Australian developed instrument used to assess health literacy ${ }^{6}$. The HLQ assesses nine independent health literacy domains to evaluate the experiences of people related to understanding and using health information ${ }^{6}$. It has been translated and validated in Brazil $^{7}$ and is internationally recognized for its clinical applicability. However, the retest reliability of the Brazilian version (HLQ-Br) has not been tested. This study aimed to determine the reliability of the HLQ-Br with a sample of Brazilian carers of older people.

\section{METHODS}

This was a test-re-test reliability study.

From May to December 2019, carers of older people who were discharged from inpatient wards at a university hospital were invited to participate. Inclusion criteria were to be $18+$ years and be an informal family carer (as described above) of an older person aged $60+$ years discharged from

\footnotetext{
1Universidade Federal de São Paulo, Escola Paulista de Medicina - São Paulo (SP), Brazil.

${ }^{2}$ Monash University - Melbourne, Australia.

${ }^{3}$ Curtin University - Bentley, Australia.

${ }^{4}$ Universidade Estadual Paulista, Faculdade de Medicina de Botucatu - Botucatu (SP), Brazil.

${ }^{5}$ Murdoch University - Murdoch, Australia.

*Corresponding author: alessandrojacinto@uol.com.br

Conflicts of interest: the authors declare there is no conflicts of interest. Funding: Fundação de Amparo à Pesquisa do Estado de São Paulo (FAPESP).

Received on December 14, 2020. Accepted on January 16, 2021.
} 
an inpatient ward of the participating hospital. A sociodemographic questionnaire was also applied during the baseline assessment.

The COSMIN guidelines ${ }^{8}$ recommend a minimum sample of 50 completed data sets to provide accurate estimates of measurement stability over time. Therefore, we aimed to recruit 50 carers for this study.

The HLQ- $\mathrm{Br}^{7}$ was administered face-to-face at baseline (pre-discharge from the hospital of the older person) and approximately two weeks later, at time point 2, the HLQ-Br was applied by telephone. The HLQ- $\mathrm{Br}^{7}$ is a 44 -item tool comprising nine domains structured as Likert scales. The first five domains use a 4-point scale to assess participants' agreement with a series of statements (responses range from "strongly disagree" to "agree"). The other four domains require participants to self-report the ease with which they feel they can complete certain health literacy-related tasks (responses range from "cannot do or always difficult" to "always easy". All HLQ scales (Australian original version), confirmed by factor analysis, have good internal consistency reliability (Cronbach's alpha ranging from $0.80-0.89)^{6}$. A recent reliability study by our team investigating retest reliability of the HLQ among carers of older people being discharged from hospitals in Australia identified moderate to high levels of retest reliability?.

The study was approved by the Ethics Committee of the institution where the study was conducted (blinded for review), and all informal carers signed a Term of Consent.

Analyses were undertaken using SPSS v25. The categorical variables were expressed as crude and relative values and associations of these variables among groups were determined using the Chi-Square test. Continuous variables were expressed as means and standard deviations (for normal distribution) and compared through Student's t-test. The nine HLQ-Br scale totals were analyzed separately, given that an overall total score for the instrument is not recommended by the authors ${ }^{6}$. Correlations were evaluated between baseline and time point 2 scores of the HLQ-Br scales using the intraclass correlation coefficient (ICC) (two-way mixed effects, absolute agreement, 95\% confidence interval $(95 \% \mathrm{CI})$ ). ICC ratings were classified as poor $<0.5$; $0.5-0.74$ moderate; $0.75-0.9$ good and values greater than 0.9 excellent $^{10}$.

\section{RESULTS}

Fifty-one carers completed the initial assessment session, with a mean age of $52.5( \pm 14.0)$ years and $41(80.4 \%)$ were female. Almost two-thirds (62.7\%) of the carers gave care daily and $54.9 \%$ lived with the person they cared for, as presented in Table 1.

The mean time for HLQ- $\mathrm{Br}$ administration was 11 $( \pm 3.7)$ minutes. The mean time between assessments was $20.8( \pm 13.3)$ days.

Only 35 participants completed the second test occasion. The most common reasons for not returning for the retest occasion were "not answering the phone after several trials" $(10(62.5 \%))$ and "refused to participate" (6 (37.5\%)). There were no significant differences between those who did and those who did not complete the second assessment except for "frequency of care" ( $\mathrm{p}=0.03)$, in which those completing the second assessment required higher levels of care. Details of the demographics of the 35 participants who did complete the retest occasion are also shown in Table 1.

Table 2 shows the mean scores for each scale and the reliability data (ICC, 95\% CI). The results indicate that the reliability estimates of the HLQ-Br (ICC, $n=35$ ) were good (that is, ranging from 0.79 to 0.89 ) for seven of the nine HLQ- $\mathrm{Br}$ scales. On the subscale, "actively managing my health", the reliability was excellent [0.925 (95\%CI 0.846-0.963)]. For the remaining scale, "navigate the healthcare system", reliability was moderate [0.725 (95\%CI 0.452-0.861)].

\section{DISCUSSION}

There has been an increase in health literacy research in Brazil over the past few years ${ }^{11}$. The World Health Organization classifies health literacy as one of the major health promotion factors for achieving or maintaining good health, which makes the topic extremely important in terms of public health ${ }^{12}$. Brazilian health literacy studies have been conducted with participants in the following disease areas - cardiology, infectious and oral diseases ${ }^{13-17}$. Previously, two Brazilian studies ${ }^{5,18}$ undertook health literacy research in carers of older people, however, neither of them used the Health Literacy Questionnaire ${ }^{6}$. Instead they preferred using the S-TOFHLA 5 and the Canadian instrument called Health Literacy ${ }^{18}$.

Australian and Brazilian researchers recently conducted a systematic review ${ }^{19}$ to identify studies on the psychometric properties of self-report health literacy assessment instruments, focussing on studies of older people or caregivers of older people. This systematic review reported that the Health Literacy Questionnaire ${ }^{6}$ was the best self-report health literacy tool across the various psychometric properties. 
Table 1. Sociodemographic data of the carers and of the older people being cared.

\begin{tabular}{|c|c|c|c|}
\hline & $\mathrm{n}=51$ & $\mathrm{n}=35$ (attended T2) & $\mathrm{n}=16$ (did not attend T2) \\
\hline Carers mean age (SD) & $52.5(14.0)$ & $53.5(14.3)$ & $50(13.5)$ \\
\hline \multicolumn{4}{|c|}{ Carers sex-n (\%) } \\
\hline Female & $41(80.4)$ & $26(74.2)$ & $15(93.7)$ \\
\hline Male & $10(19.6)$ & $9(25.8)$ & $1(6.3)$ \\
\hline \multicolumn{4}{|c|}{ Schooling (years)-n (\%) } \\
\hline $1-9$ & $15(29.4)$ & $9(25.8)$ & $7(43.7)$ \\
\hline $10-12$ & $20(39.2)$ & $13(37.1)$ & $6(37.5)$ \\
\hline$\geq 13$ & $16(31.4)$ & $13(37.1)$ & $3(18.8)$ \\
\hline \multicolumn{4}{|c|}{ Relationship to older person you care for- $n(\%)$} \\
\hline Wife & $5(9.8)$ & $4(11.4)$ & $1(6.2)$ \\
\hline Husband & $3(5.9)$ & $3(8.6)$ & $0(0)$ \\
\hline Son/daughter & $30(58.8)$ & $22(62.9)$ & $10(62.6)$ \\
\hline Grandson/granddaughter & $3(5.9)$ & $2(5.7)$ & $1(6.2)$ \\
\hline Others & $10(9.8)$ & $4(11.4)$ & $4(25.0)$ \\
\hline \multicolumn{4}{|c|}{ Frequency of care-n (\%)* } \\
\hline Every day & $32(62.7)$ & $23(65.7)$ & $8(50.0)$ \\
\hline Several times a week & $10(19.6)$ & $9(25.8)$ & $2(12.5)$ \\
\hline At least once a week & $4(7.8)$ & $2(5.7)$ & $2(12.5)$ \\
\hline Less often & $5(9.8)$ & $1(2.8)$ & $4(25.0)$ \\
\hline \multicolumn{4}{|c|}{ Dwelling-n (\%) } \\
\hline With the older person & $28(54.9)$ & $19(54.3)$ & $8(50.0)$ \\
\hline Visits the person they care for & $22(43.1)$ & $16(45.7)$ & $7(43.7)$ \\
\hline Caring by telephone & $1(1.9)$ & $0(0)$ & $1(6.2)$ \\
\hline
\end{tabular}

${ }^{*} \mathrm{p}<0.05$ (Chi-Square); T2: Time 2.

Table 2. Retest reliability of nine Health Literacy Questionnaire in Brazilian scales.

\begin{tabular}{|c|c|c|c|}
\hline \multirow[b]{2}{*}{ Scales } & \multicolumn{3}{|c|}{ Included only $(n=35)$} \\
\hline & T1 M (SD) & $\mathrm{T} 2 \mathrm{M}(\mathrm{SD})$ & ICC $(95 \% \mathrm{Cl})$ \\
\hline \multicolumn{4}{|c|}{ Range 1 (lowest)-4 (highest) } \\
\hline $\begin{array}{l}\text { 1. Feeling understood and supported by healthcare } \\
\text { providers }\end{array}$ & $3.11(0.61)$ & $2.98(0.41)$ & $0.775(0.558-0.886)$ \\
\hline 2. Having sufficient information to manage my health & $2.98(0.50)$ & $2.87(0.49)$ & $0.891(0.774-0.946)$ \\
\hline 3. Actively managing my health & $2.71(0.62)$ & $2.60(0.65)$ & $0.925(0.846-0.963)$ \\
\hline 4. Social support for health & $3.05(0.72)$ & $2.88(0.58)$ & $0.808(0.618-0.903)$ \\
\hline 5. Appraisal of health information & $3.08(0.56)$ & $3.05(0.41)$ & $0.828(0.658-0.913)$ \\
\hline \multicolumn{4}{|c|}{ Range 1 (lowest)-5 (highest) } \\
\hline 6. Ability to actively engage with healthcare providers & $3.74(1.09)$ & $3.85(0.84)$ & $0.864(0.733-0.931)$ \\
\hline 7. Navigate the healthcare system & $3.58(0.87)$ & $3.52(0.79)$ & $0.725(0.452-0.861)$ \\
\hline 8. Ability to find good health information & $3.82(0.82)$ & $3.97(0.74)$ & $0.791(0.591-0.894)$ \\
\hline $\begin{array}{l}\text { 9. Understand health information enough to know what } \\
\text { to do }\end{array}$ & $4.05(0.72)$ & $3.77(0.91)$ & $0.837(0.634-0.923)$ \\
\hline
\end{tabular}

T1: Time 1; M: Mean; SD: Standard deviation; T2: Time 2. 
The validation study ${ }^{7}$ of the Health Literacy Questionnaire in Brazil did not involve older people or caregivers of older people, therefore, testing the reliability of this instrument for this population is important. We found that reliability was good or excellent in most of the nine scales of the instrument, making it a reliable instrument to be used for assisting carers of older people, especially at the time of hospital discharge of the person being cared for.

Limitations of the present study included that the study sample was smaller than the desired sample, because of $31.3 \%$ dropouts for the second assessment. However, the final sample of thirty-five did not differ from the participants who did not return for the reassessment, except on one item (frequency of care), in which those completing the second assessment required higher levels of care. In addition, the sample was recruited from inpatient clinics at a single university hospital, and so may not be representative of carers of older people associated with other hospitals, or other recruitment avenues.

\section{CONCLUSIONS}

The Brazilian version of the Health Literacy Questionnaire is a reliable tool to assess health literacy in carers of older people.

\section{ACKNOWLEDGMENT}

We thank all the carers of older people who accepted to participate in the study.

\section{AUTHORS' CONTRIBUTIONS}

AFJ: Conceptualization, Funding acquisition, Formal Analysis, Writing - original draft. KH: Writing - review \& editing. CT: Funding acquisition, Writing - review \& editing. MF: Data curation. AB: Data curation. SS: Writing - review \& editing. EB: Formal Analysis, Writing - review \& editing.

\section{REFERENCES}

1. Brasil. Instituto Brasileiro de Geografia e Estatística (IBGE). Projeção da população do Brasil e das Unidades da Federação [cited on 2020 Sep 14]. Available from: https://www.ibge.gov. br/apps/populacao/projecao/.

2. Garcez-Leme LE, Leme MD. Costs of elderly health care in Brazil: challenges and strategies. Medical Express São Paulo, (online). 2014:1(1). https://doi.org/10.5935/MedicalExpress.2014.01.02

3. U.S. Department of Health and Human Services, Office of Disease Prevention and Health Promotion. National action plan to improve health literacy. 2010 [cited 2013 Feb 27]. Available from: https://health.gov/our-work/health-literacy/ national-action-plan-improve-health-literacy.

4. Australian Commission on Safety and Quality in Health Care. National Statement on Health Literacy. Canberra, ACT: ACSQHC; 2014. Available from: https://www.safetyandquality. gov.au/sites/default/files/migrated/Health-Literacy-NationalStatement.pdf.

5. Almeida KMV, Toye C, Silveira LVA, Slatyer S, Hill K, Jacinto AF. Assessment of functional health literacy in Brazilian carers of older people. Dement Neuropsychol. 2019;13(2):180-6. https://doi.org/10.1590/1980-57642018dn13-020006

6. Osborne RH, Batterham RW, Elsworth GR, Hawkins M, Buchbinder R. The grounded psychometric development and initial validation of the Health Literacy Questionnaire (HLQ). BMC Public Health. 2013;13:658. https://doi.org/10.1186/14712458-13-658

7. Moraes KL, Brasil VV, Mialhe FL, Sampaio HAC, Sousa ALL, Canhestro MR, et al. Validation of the Health Literacy Questionnaire (HLQ) to brazilian portuguese. Acta Paul Enferm. 2021;34:eAPE02171. https://doi.org/10.37689/ acta-ape/2021AO02171

8. Prinsen CAC, Mokkink LB, Bouter LM, Alonso J, Patrick DL, de Vet $\mathrm{HCW}$, et al. COSMIN guideline for systematic reviews of patient- reported outcome measures. Qual Life Res. 2018;27(5):1147-57. https://doi.org/10.1007/s11136-018-1798-3

9. Burton $E$, Toye $C$, Slatyer $S$, Jacinto $A F$, du Preez J, Bronson $M$, Hill KD. Testing the reliability of the Health Literacy Questionnaire with carers of older adults receiving hospital care. Australas J Aging. 2021;40(2):213-7. https://doi.org/10.1111/ajag.12897

10. Koo TK, Li MY. A guideline of selecting and reporting intraclass correlation coefficients for reliability research. J Chiropr Med. 2016;15(2):155-63. https://doi.org/10.1016/j.jcm.2016.02.012

11. Moraes KL. Health literacy: a long journey to brazilian health practices. Health Lit Res Pract. 2018;2(3):e161-e162. https:// doi.org/10.3928/24748307-20180807-01

12. United Nations Economic and Social Council. ECOSOC Annual Ministerial Review. Regional preparatory meeting on promoting health literacy. Beijing, China, 29-30 April 2009 [Internet]. Available from: https://www.un.org/en/ecosoc/newfunct/pdf/ chinameetinghealthliteracybackground paperv2.pdf.

13. Tenani CF, De Checchi MHR, Bado FMR, Ju X, Jamieson L, Mialhe $\mathrm{FL}$. Influence of oral health literacy on dissatisfaction with oral health among older people. Gerodontology. 2020;37(1):4652. https://doi.org/10.1111/ger.12443

14. Costa VRS, Costa PDR, Nakano EY, Apolinário D, Santana ANC. Functional health literacy in hypertensive elders at primary health care. Rev Bras Enferm. 2019;72(suppl 2):26673. https://doi.org/10.1590/0034-7167-2018-0897

15. Cunha GH, Galvão MTG, Pinheiro PNC, Vieira NFC. Health literacy for people living with HIV/Aids: an integrative review. Rev Bras Enferm. 2017;70(1):180-8. https://doi.org/10.1590/00347167-2015-0052

16. Cruvinel AFP, Méndez DAC, Chaves GC, Gutierres E, Lotto $M$, Oliveira $T M$, et al. The brazilian validation of a health literacy instrument: the newest vital sign. Acta Odontol Scand. 
2018;76(8):587-94. https://doi.org/10.1080/00016357.201 8.1484511

17. Firmino RT, Granville-Garcia $A F$, McGrath $C P$, Bendo $C B$, Ferreira FM, Paiva SM. Validation for brazilian portuguese language of the Hong Kong oral health literacy assessment task for paediatric dentistry (BOHLAT-P). Int J Paediatr Dent. 2020;30(2):234-43. https://doi.org/10.1111/ipd.12585
18. Queiroz JPC, Machado ALG, Vieira NFC. Health literacy for caregivers of elders with Alzheimer's disease. Rev Bras Enferm. 2020;73(Suppl 3):e20190608. https://doi.org/10.1590/00347167-2019-0608

19. Slatyer S, Toye C, Burton E, Jacinto AF, Hill KD. Measurement properties of self-report instruments to assess health literacy in older adults: a systematic review. Disabil Rehabil. 2020;1-17. https://doi.org/10.1080/09638288.2020.1836044 